\title{
Identidade cultural do coco babaçu
}

\section{Cultural identity of the babassu coconut}

COSTA, Andrea; Mestre; Universidade Federal do Maranhão - UFMA andrea.katianefc@gmail.com

LÚCIO, Mariana; Graduanda; Universidade Federal do Maranhão - UFMA

marianagomesla@gmail.com

SILVA, Daniele; Graduanda; Universidade Federal do Maranhão - UFMA

mushima2013@hotmail.com

SARAIVA, Gisele; Mestre; Universidade Federal do Maranhão - UFMA gisarco@gmail.com

NORONHA, Raquel; Doutora; Universidade Federal do Maranhão - UFMA

raquelnoronha79@gmail.com

\section{Resumo}

O presente artigo propõe refletir a atividade projetual de designers enquanto mediadores de relações para empoderamento na comunidade de São Caetano, situada no município de Matinha, Maranhão; utilizando-se da pesquisa etnográfica e dos conhecimentos e práticas do design colaborativo e metaprojetual. Em contexto de conflito territorial e limitação da obtenção do coco babaçu - matéria-prima essencial às atividades tradicionais do núcleo do Movimento Interestadual das Quebradeiras de Coco Babaçu (MIQCB), presente na região, que garante renda e contribui para a identidade local. Apresenta-se o projeto que junto a comunidade repensou a relação com o coco, a fim de estimular o envolvimento dos jovens nas atividades artesanais e a ideação de novos produtos.

Palavras Chave: Design colaborativo; identidade cultural; metaprojeto.

\section{Abstract}

The present article proposes to reflect the designer's project activity as relations mediator for empowerment in the community of São Caetano, located in the city Matinha, Maranhão; using ethnographic research and the knowledge and practices of collaborative design and metaproject. In the context of territorial conflict and limitation of the extraction of babaçu coconut - essential raw material to the traditional activities of the core of Movimento Interestadual das Quebradeiras de Coco Babaçu (MIQCB), present in the region, which guarantees income and contributes to local identity. We present the project that together to the community rethought the relationship with the babaçu coconut, in order to stimulate the involvement of young people in craft activities and the creation of new products.

Keywords: Colaborative design; cultural identity; metaproject. 


\title{
1 Introdução
}

A globalização atrelada aos ideais capitalistas trouxe consigo a industrialização e esta, a praticidade e menor gasto de tempo na produção de artefatos, com o sistema seriado e diversos outros sistemas industriais criados. Porém, isto fez com que alguns ciclos naturais fossem interrompidos, fazendo com que o saber fazer artesanal fosse sobreposto pelo industrial ou acadêmico. Diversas vezes o artesanato, recebe associações negativas (como lento, mal-acabado, etc.), sendo colocado na base de uma hierarquia sufocante, onde quanto mais básico menos relevante. A figura do artesão foi questionada, afastando-os da evolução moderna, marginalizando suas oralidades, consequentemente a sua transmissão hereditária foi prejudicada pelo êxodo de buscas por saberes mais reconhecidos, adquirindo uma imagem romantizada.

Diante a saturação provocada pela evolução moderna, deu-se voz a diálogos e debates sobre sustentabilidade; a visão industrial, representada nas figuras dos designers, volta o olhar ao artesanato, mas dessa vez mais cuidadoso sobre a compreensão dos ciclos e sistemas. A criação de relações entre pesquisadores em design e artesãos, apresentam resultados inovadores, criando e propondo soluções e reflexões, que beneficiam atores sociais que estão envolvidos durante e após o processo. É por meio de uma visão descentralizadora dos designers que desenvolveu-se esta pesquisa, utilizando metodologias participativas que perpassam pelos campos do design, antropologia, psicologia e geografia. Lima destaca a relevância destes conhecimentos:

\begin{abstract}
Saberes que se mantiveram no tempo porque são dotados de criatividade extrema. Tanto que foram reconhecidos como insumo primário das indústrias criativas, um dos setores da economia mais recentemente criados. Fruto do conhecimento de longa duração, que remete ao passado, à história e à tradição, o artesanato é, portanto, também um discurso sobre o mundo contemporâneo, um campo que põe em diálogo o homem e a sua capacidade inventiva (LIMA in SANTOS et al (org), 2016, p. 9).
\end{abstract}

Segundo John Thackara (2008, p.39), os designers precisam promover novas relações fora das zonas de conforto, aprender novas formas de colaborar e conduzir projetos. Além de melhorar a capacidade de todos os cidadãos de envolvimento em um diálogo significativo sobre seu ambiente e contexto, promovendo novos relacionamentos entre as pessoas que produzem e as pessoas que consomem. Na busca de uma sociedade e relações humano-objeto mais humanizadas, que observa cautelosamente ciclos e valores culturais, os designers moveram-se de uma escala hierárquica proposta (ou forçada) pelo modelo moderno a um meio coletivo criativo, que flexiona e troca sem precisar imperar, como nos diz Noronha, 2011:

\footnotetext{
Desta forma, talvez seja possível nos posicionarmos de uma forma estratégica no sistema de produção imposto como um padrão, possibilitando que tenhamos, nas nossas atividades profissionais e acadêmicas, uma postura de tradutores efetivos e não de reprodutores de linguagem. Propomos, com isto, um deslocamento, do centro dos processos para o meio deles, entre os artesãos e os consumidores, como uma estratégia de melhor nos alfabetizarmos na linguagem do outro, mediando assim o léxico específico daquelas comunidades, do mercado e o repertório teórico do nosso campo de atuação (NORONHA, 2011, p. 127).
}

Propondo este olhar holístico, de meio (colaborador), e menos de centro (protagonista), os designers e suas atuações contemporânea tem rompido a disciplinaridade e buscado a multi e interdisciplinaridade com mais fervor, provocando mudanças essenciais na área do Design. Nessa 
posição de mediação, a figura dos designers revelam-se "diplomatas" entre os sistemas de produção e consumo, olhando com mais cuidado o indivíduo e sociedade, na busca por potencializar esta relação da melhor forma possível e, por que não, da forma mais sustentável possível. Aliando os saberes, ambos importantes, o design investiga e expõe a expressão do produto artesanal; de como os atores materializam sua identidade cultural, por meio das metodologias colaborativas, assumindo que cada um desses atores sociais são, como Noronha (in Oliveira et al, 2017) defende, designers orgânicos. Desse ponto, promover a valorização destes, contribuindo para sua emancipação e superação social (que está diretamente ligada a sustentabilidade quista e idealizada).

\section{Contexto do projeto}

Movidos pela busca da humanização na relação produção-consumo e dispostos a entender e valorizar, por meio do design, as cadeias produtivas das atividades artesanais, o Núcleo de pesquisa em Inovação, Design e Antropologia - NIDA da Universidade Federal do Maranhão - UFMA, tem atuado em cooperação e colaboração às comunidades artesanais do interior do Maranhão. Para esta reflexão e relato, falamos das atividades realizadas pelo projeto de extensão 'A Identidade Cultural do Coco Babaçu: processos colaborativos de empoderamento entre designers, quebradeiras de coco e suas famílias' que ocorreu entre 2016 e 2017, no intervalo de um ano, em conjunto com o Movimento Interestadual das Quebradeiras de Coco Babaçu - MIQCB - da comunidade de São Caetano, no município de Matinha (MA). Intermediadas em especial por Rosenilde Gregório dos Santos Costa, a Rosa, uma das lideranças do movimento no município, nos aproximamos das questões que envolvem a prática artesanal do local.

As quebradeiras, que tem como produto final o azeite de coco e o mesocarpo do babaçu (muito utilizado na alimentação escolar e na produção de bolos) comercializados nas feiras regionais do município e entornos com grande potencial socioeconômico, tem, ao longo dos últimos anos, sofrido impedimentos na atividade de extração do coco babaçu, apesar de existirem leis protegendo sua prática (NORONHA et al, 2017, p. 102, rodapé). Uma disputa territorial contra os fazendeiros locais que tem cercado os terrenos contra o acesso das artesãs, além de estarem realizando derrubadas e queimadas dos babaçuais (Figura 1). As quebradeiras relatam que têm perdido seus quintais para pessoas que não atuam ou moram na comunidade (NORONHA et al, 2017, p.106). O cercamento das terras pelos fazendeiros desconsidera o seu trabalho e desrespeita o seu livre exercício, mas ainda assim elas são ameaçadas ao reivindicar o direito as suas atividades. 
Figura 1 - Arame farpado cercando as terras e as queimadas feitas.

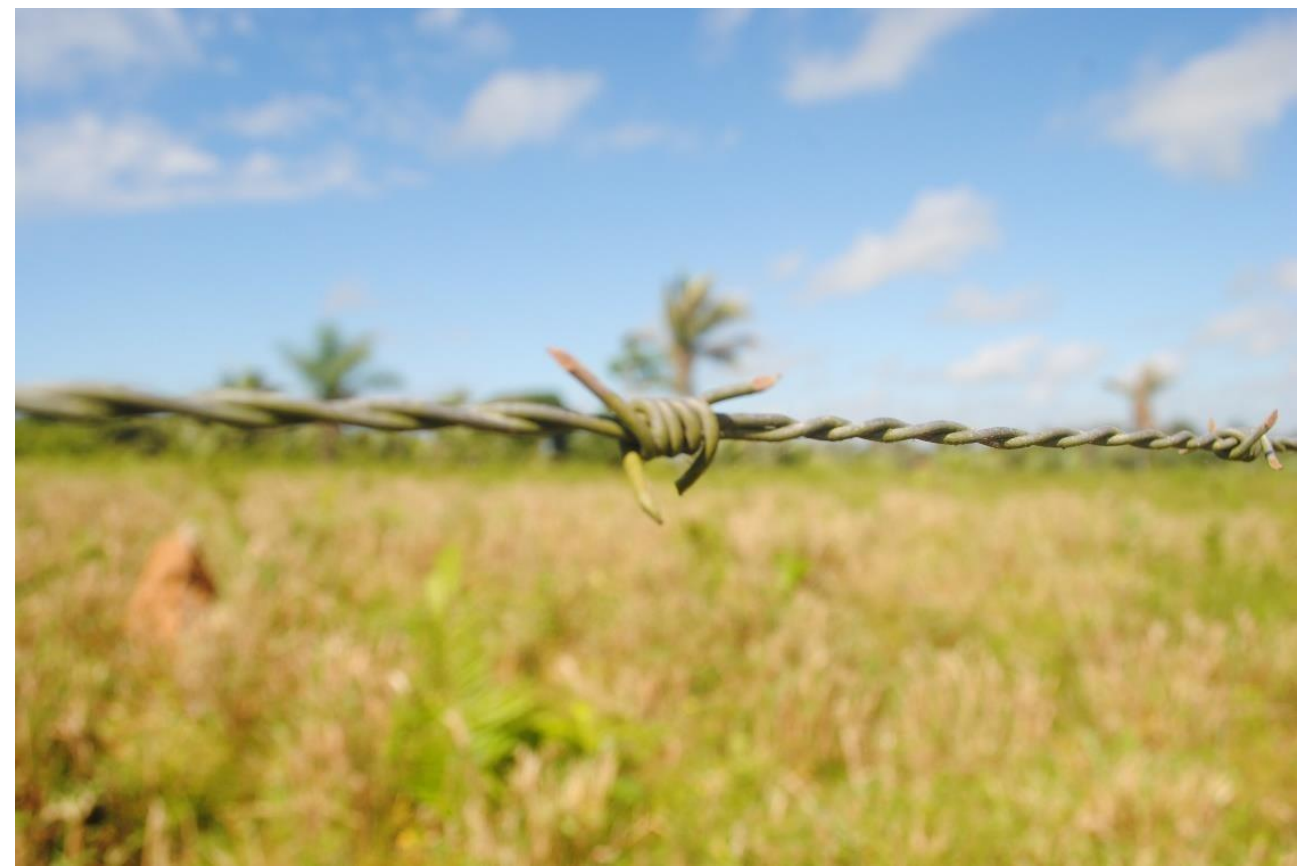

Fonte: das autoras (2017).

Com essa limitação, e enquanto lutam em resistência ao direito de manterem-se atuantes, o NIDA agiu em cooperação à busca de soluções alternativas e viáveis de produção, levando em consideração o contexto atual, e visando inserir os jovens nas atividades artesanais, como forma de mantê-los distantes de vulnerabilidades sociais, propondo tal atividade como uma de suas formações e de agregar na resistência. Objetivando contribuir à visibilidade e preservação da prática, cultura, memória e identidade - com isso, afirmando o valor da atividade e estabelecendo a troca de saberes como saber fazer artesanal - da comunidade de São Caetano.

\section{Metodologia aplicada}

Segundo Noronha (2011, p. 127), a aproximação e construção coletiva da identificação de valores é um processo em análise, por isso, para garantir uma abordagem comprometida em respeitar a comunidade artesanal em questão, revisitamos a etapa de revisão de literatura, contemplando conceitos como o de 1) tecnologias sociais, 2) pesquisa etnográfica, 3) cartografia social, 4) design colaborativo, 5) metaprojeto, 6) inovação social e 7) design terroir. Debatendo e dialogando com estas temáticas para entendermos mais profundamente a metodologia estudada para a aplicação em campo, com as suas possíveis flexões de contexto.

A organização das etapas metodológicas, de caráter reflexivo como proposto pelo processo metaprojetual, foi pré-estabelecida, porém cientes de que a ida ao campo poderia reorganizá-las e propor novas etapas. Dando ênfase a momentos de diálogos e vivências in locu, buscamos estar perto das práticas e dos discursos das artesãs para entender as qualidades e valores já existentes expressados nos produtos, a fim de compreender a partir de que ponto se daria a construção 
coletiva de identificação e reconhecimento dos demais aspectos de produção e territoriais (Krucken, 2009, p.23).

O quadro a seguir (Quadro 1), apresenta as etapas pré-estabelecidas, junto aos verbos e sentidos que se relacionam a busca em cada uma delas. Na prática do campo, a comunidade se mostrou tão interessada na nossa atividade que cooperou de tal forma a não serem necessárias maiores mudanças no processo. A mudança mais significativa foi a abertura do foco, que estava a inicialmente voltada aos jovens; não significando que eles foram negligenciados, já que tivemos o zelo de observar seus comportamentos durante toda a vivência.

Quadro 1 - Ações, verbos e sentidos das etapas.

\begin{tabular}{|c|c|c|c|}
\hline Etapa & Ações & Verbo & Sentido \\
\hline & Acesso acompanhado & Reconhecer & Observar \\
\hline \multirow[t]{2}{*}{ COMPREENSÃO } & Entrevistas abertas & Conhecer & Ouvir \\
\hline & Rodas de conversa & Entender & Equilibrar \\
\hline \multirow[t]{2}{*}{ COCRIAÇÃO } & Oficinas de cocriação & Propor & Direcionar \\
\hline & Oficina de produção & Produzir & Tatear \\
\hline
\end{tabular}

Fonte: das autoras.

O metaprojeto aliado ao codesign, descentraliza os designers do processo da pesquisa, fazendo com que não existam hierarquias entre artesãos e designers, respeitando o saber fazer tradicional. Suscitando novas soluções e modificações durante todo o processo da pesquisa. Além disso, o método cartográfico explana sobre a necessidade de levar em consideração os efeitos que uma pesquisa pode sofrer pelas diversas variáveis externas envolvidas durante o processo de pesquisa. Sendo necessário respeitar o espaço e o tempo dos participantes, além das suas opiniões, como pode ser observado no discurso de Eduardo Passos e Regina Barros, sobre a cartografia.

A diretriz cartográfica se faz por pistas que orientam o percurso da pesquisa sempre considerando os efeitos do processo do pesquisar sobre o objeto da pesquisa, o pesquisador e seus resultados. (PASSOS e BARROS, 2009, p.17).

\subsection{Construção do percurso etnográfico}

O momento de acesso para reconhecimento do contexto, ambiente e comunidade foi bastante dificultado devido ao clima e conflitos existentes; também agravado pelo apoio participativo da facilitadora (Rosa) na luta territorial que envolve os povos Gamela, no município de Matinha. Além disso, a comunicação telefônica foi dificultada pela pouca presença de torres de 
sinais de telefonia na região, fazendo com que o contato com a comunidade fosse feito por etapas, apresentou-se o projeto à comunidade, havendo o reconhecimento da cadeia produtiva dos núcleos do MIQCB do município, visitou-se os espaços de trabalho das artesãs (oficina na sede de São Caetano e fábrica na sede de Bom Jesus) sendo apresentados os ambientes locais (a comunidade, terras cercadas), mapeando os lugares de conflito.

A segunda ação escrita no Quadro 1, entrevistas abertas, fez parte de todo o processo, como pode ser pressuposto, as entrevistas aconteceram durante todos os contatos, num exercício de escuta para conhecer as histórias, memórias, experiências e informações que revelaram os detalhes do contexto vivido por elas. Ouvindo e provocando falas, entendemos a importância de tornar visível a outros grupos e contextos, as questões levantadas pelo enfrentamento destas mulheres, como forma de ativar sentido de responsabilidade, para contribuir na luta em favor do equilíbrio das atividades da comunidade, potencializando suas vozes.

Para as rodas de conversas, com um corpo maior de participantes, intento-se sincronizar os relatos, fazendo das memórias de umas o gatilho para as memórias de outras e assim compreender o contexto numa dinâmica diferente do contato individualizado. Tanto nas conversas quanto nas entrevistas foram possíveis agregar relatos e descrições de caráter sociopolítico, no que se refere à resistência da atividade e a luta por sua manutenção, e de caráter econômico e produtivo, no que se refere as etapas e fases da cadeia produtiva do coco. Também nos aproximamos da linguagem da comunidade, deste modo fez-se bastante perceptivo a importância e valor do coco babaçu para a comunidade, em expressões como "nosso ouro da floresta" e falas como as de Maria Antônia, que se reconhece por meio do coco e atividades geradas:

Eu sou Maria Antônia Trindade Mendes, moro aqui no quilombo São Caetano, pelo que eu tô vendo que vocês tão falando que são professoras, eu acho que eu também sou professora, na minha roça, no meu trabalho de coco, no meu trabalho daqui da luta, eu acho que eu também sou professora por que eu já tô com 61 anos eu nunca desisti. (NORONHA et al, 2017, p. 106)

\subsection{Oficina de cocriação e produção}

Como consequência da etapa etnográfica, a realização da oficina fez com que houvesse um processo de cocriação, criando novas relações entre os conhecimentos. As atuações dos designers neste processo não se restringe a perpassar conhecimentos, mas também busca introduzir processos sustentáveis, não apenas para o ambiente, mas para toda a cadeia de produção. Estes processos sustentáveis estão diretamente ligados a uma produção com métodos menos agressivos, adequado a idade e a força física de cada artesão. Realizou-se este processo na sede do MIQCB da comunidade, que contava com espaço e suporte apropriado para a realização das atividades (Figura 2). 
Figura 2 - Oficina de cocriação em São Caetano.

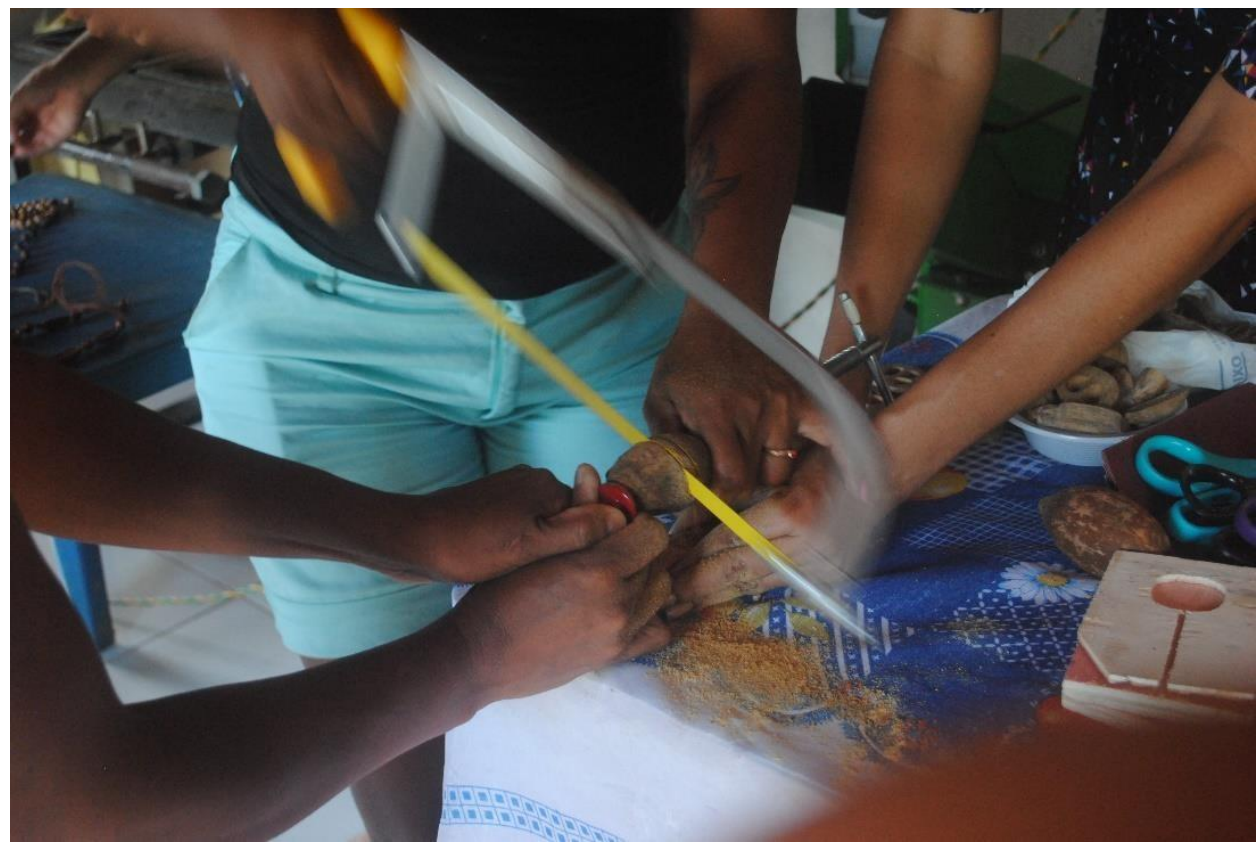

Fonte: das autoras (2017).

Baseados na experiência construída com o MIQCB em Esperantina (PI), que atuou junto com os jovens do Projeto Pindova (Portela, et al, 2016), definimos como meta a promoção da oficina de cocriação em São Caetano trabalhando com a representação gráfica do coco e à produção de produtos diversos que faça uso deste como carimbo ou como detalhe em peças como almofadas e bolsas (Figura 3). Além disto, houve a produção de biojóias que contou com a utilização de sementes da flora local, fazendo com que houvesse a otimização do processo por meio do aproveitamento total das matérias primas.

Ao trabalhar com a imagem do coco babaçu, foi possível observar a relação entre os artesãos e o coco criar novas perspectivas, fazendo com que a percepção que a imagem do coco que fora endurecida devido a repetição das atividades e pela atual luta. Trabalhar com a representação visual do coco como carimbo contribui para dinamizar e suavizar esta imagem, além de ampliar as possibilidades de produção artesanal, tão importante para este momento de conflito onde se faz extremamente necessário aproveitar o máximo possível do coco. Junto a técnicas de macramê e costura, o momento de produção contou com a participação dos jovens, adultos e idosos, em sua maioria mulheres, porém com quantidade relevante de homens jovens. 
Figura 3 - O coco babaçu como carimbo.

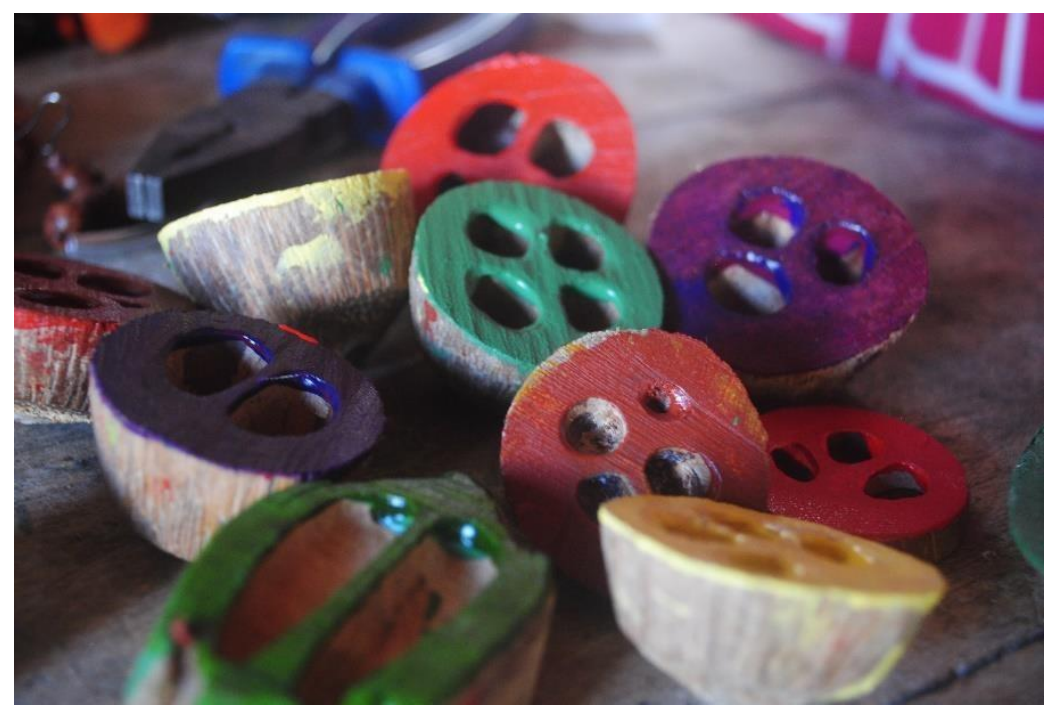

Fonte: das autoras (2017)

Observou-se que diante das etapas de produção dos artefatos, houve uma divisão entre os participantes da oficina, onde os jovens participaram ativamente da produção das biojóias e as mulheres idosas da produção de almofadas e bolsas, que apresentam maior exigência de minuciosidade (como costurar), se mostrando mais estimulados pelas etapas com maior expressão criativa. Surpreendidos pela diversidade do uso do coco e das diversas sementes encontradas na região, houve uma intensa participação da comunidade que continuou a produzir algumas propostas de produtos apresentadas, adaptando aquilo aos seus gostos, seu imaginário e sua criatividade. Algumas artesãs mais jovens mostraram que já exploravam o potencial do coco, antes da nossa chegada na comunidade, guiando os demais na produção de novos produtos.

\section{Resultados}

Durante o contato, percebemos a conexão dos indivíduos e suas atividades com o ambiente, numa relação explícita para além da coexistência, mas sim de pertencimento presente no forte reconhecimento de si e de seus trabalhos nas relações com o espaço e matéria-prima, o coco babaçu. Não simplesmente um espaço qualquer que se desconecta e se refaz em qualquer outro, mas um espaço-ser, que se costura junto a eles, em histórias, memórias e significados. Uma relação de ser a partir do lugar e do tempo como Portela et al $(2016$, p.5623) discorre "a identidade cultural tem a ver com o tempo e lugar que se vive".

A identificação com as atividades do coco é tão forte que elas se mobilizam e se mantêm abertas para qualquer outra atividade que venha a somar com essa imagem de forma positiva. Após a nossa permanência na comunidade, fomos informados da continuidade da exploração da imagem do coco. Se mantiveram entusiasmados na produção e ideação de novos produtos, usando o coco como carimbo ou detalhe. Os jovens, segundo Maria da Glória (NORONHA et al, 2017, p.111), constantemente iam até sua casa para continuar suas produções, motivados. 
Na surpresa das artesãs com a diversidade de uso do coco babaçu, apresentado de maneira simples, de baixo custo, usando da matéria-prima que faz parte do contexto e identidade da local, com fácil aplicabilidade, contribuindo (mesmo que discretamente) a sua sustentabilidade, notou-se que a inovação social não precisa necessariamente advir de propostas mirabolantes. Tal constatação é reflexo positivo da inferência participativa e/ou colaborativa dos designers, que construindo junto à comunidade, como John Thackara $(2008$, p.39) propõe, promoveram soluções fora da zona de conforto, num processo de aprendizagem de novas formas de colaborar e conduzir projetos. Completando com Azevedo (in Santos et al, 2016, p.135), que defende que "[...] desenvolver a dinâmica dos produtos artesanais é promover o crescimento cultural de uma comunidade ou região", portanto entendemos que demos juntos um passo à frente, de muitos passos que virão, e plantamos sementes que irão brotar por meio da motivação dos jovens e artesãs.

Figura 4 - Produtos fruto da oficina.

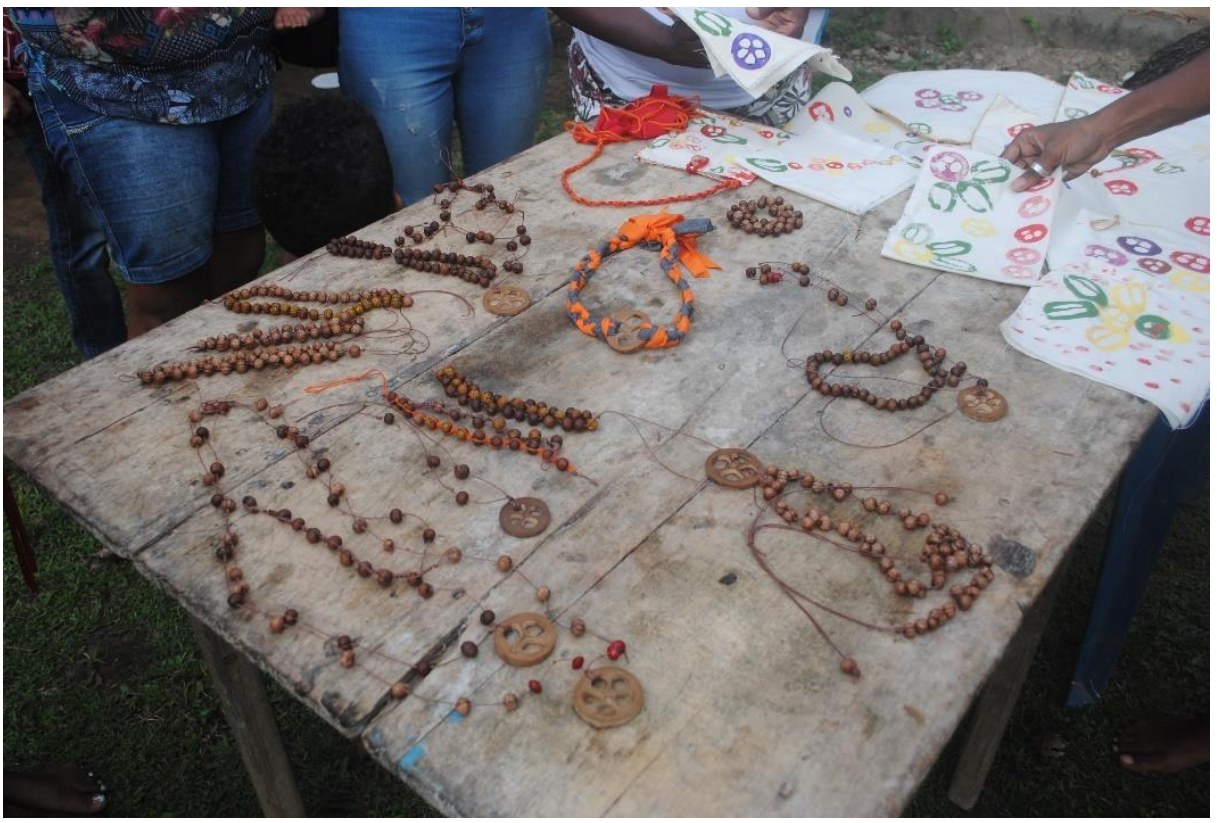

Fonte: das autoras (2017).

Após o processo em campo houve a análise dos dados, transformando estas vivências para além dos resultados da oficina, mas também produzindo uma cartografia (Figura 5), que compõe o livro "Ciranda de saberes: percursos cartográficos e práticas artesanais em Alcântara e na Baixada maranhense." produzido em 2017 pelo NIDA. A cartografia busca apresentar de maneira visual as falas, produtos e informações obtidas por meio da prática etnográfica, como pode ser observado a seguir. 
Figura 5 - Cartografia.

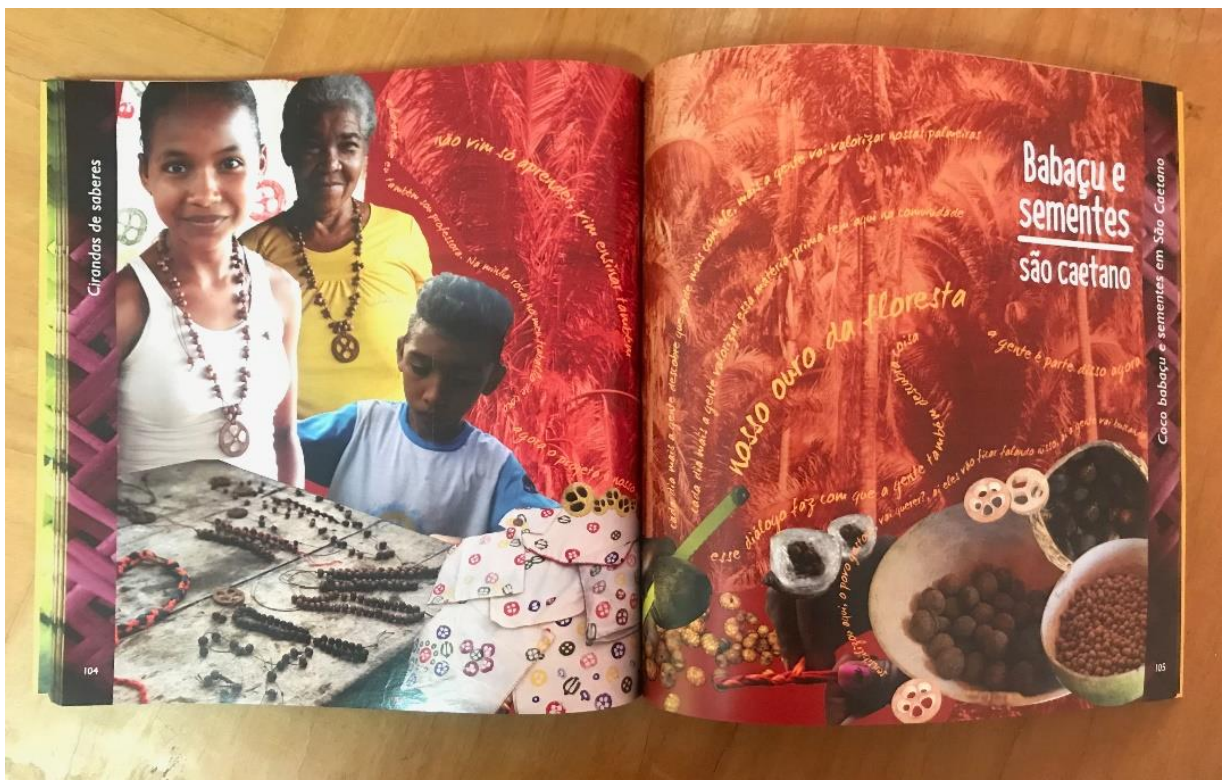

Fonte: das autoras (2017).

\section{Conclusão}

A possibilidade de trabalhar com o artesanato, a implantação de tecnologias sociais e a valorização do saber fazer tradicional e da cultura local, permite aos designers uma nova perspectiva de atuação. Dessa forma, mantendo as atividades e projetos dentro da proposta da cultura projetual, respeitando os sujeitos de pesquisa em seus contextos e fora deles. Tendo consciência do sistema sob uma perspectiva sustentável, entendemos e concordamos com Enzio Manzini e Anna Meroni, no prefácio de Krucken (2009, p.11), e demais autores que postulam sobre a unicidade existente entre o ambiente e o social, promovendo a valorização do produto territorial e artesanal na observância da construção sócio-geográfica. Assumindo que acessar essa construção é acessar também o 'saber' em oralidade dessa comunidade, e que é através dele que também o artesanato se mantém enquanto 'fazer'.

O artesanato acrescenta à racionalidade dos projetos modernos valores como a intuição (sensibilidade) e a improvisação (criatividade) que se harmoniza com a complexidade presente nos projetos contemporâneos (NORONHA et al, 2017, p.7). Faz-se preciso preservar esse diálogo entre design e artesanato e torná-lo cada vez mais harmonioso e respeitoso, para que não haja novas propostas hierárquicas que sufoquem um ou outro, pois o design que media como, coloca Portela et al (2016, p. 5624), precisa interpretar também os elementos sociais, ambientais (socioambientais) e econômicos presentes na comunidade e, porque não, sociedade. Para que assim, o artesão seja valorizado enquanto 'artesão' e promover a compreensão e valorização dele para ele mesmo.

Ao desenvolver esta oficina, houve um processo de suscitar o imaginário dos atores envolvidos, tornando possível a geração de novos produtos para a comunidade, produtos estes que estão entrelaçados com o sentimento de identidade associando as matérias primas as lutas que são 
necessárias para sua obtenção. Além disso, é possível observar que os resultados alcançados vão além daqueles planejados, exaltando o poder do campo de pesquisa como fator diferencial.

Ao integrar os artesãos a todas as etapas, tirando-os de sujeitos da pesquisa para participantes ativos, fazendo com que eles participem e construam as etapas da pesquisa com os pesquisadores, respeitando o tempo e o espaço no qual estão inseridos. Observa-se que há uma valorização não apenas do trabalho realizado por eles como artesãos, mas também de seu imaginário, seus conhecimentos, teorias e pensamentos; muitas vezes apreendidos de forma livre, ao longo de seus processos de produção. Compreendendo que para que haja transformação cultural é preciso de uma oposição à ordem estabelecida, então que usemos o respeito e o entendimento sobre sustentabilidade para modificar e otimizar o sistema de relações de saberes e fazeres vigente, e a partir disto fortalecer a parceria entre os saberes do Design e do Artesanato.

\section{Referências}

INGOLD, Tim. Trazendo as coisas de volta à vida: emaranhados criativos num mundo de materiais. In: Horizontes Antropológicos, Porto Alegre, ano 18, n.37, p. 25-44, jan./jun. 2012.

KRUCKEN, Lia. Design e território: valorização de identidades e produtos locais. São Paulo: Studio Nobel, 2009.

MANZINI, Ezio. Design, when everybody designs. An introduction to Design for Social Innovation. The MIT Press: Cambridge/London, 2015.

MORAES, Dijon De. Metaprojeto: o design do design. São Paulo: Blucher, 2010.

MOREIRA, Denilson Santos; NORONHA, Raquel Gomes; CARACAS, Luciana Bugarin; CESTARI, Glauba Alves do Vale (org.). Artesanato no Maranhão: práticas e sentidos. São Luís: EDUFMA, 2016.

NORONHA, Raquel (org.). Identidade é valor: as cadeias produtivas do artesanato de Alcântara. São Luís: EDUFMA, 2011.

NORONHA, Raquel; COSTA, Andrea; SARAIVA, Gisele; GUIMARÃES, Márcio; PORTELA, Raiama (org.). Ciranda de saberes: percursos cartográficos e práticas artesanais em Alcântara e na Baixada maranhense. São Luís: EDUFMA, 2017.

OLIVEIRA, Alfredo; FRANZATO, Carlo; GAUDIO, Chiara Del (orgs). Editora Blucher. 2017. Simpósio de Design Sustentável 2015. Capítulo 22, p 277-294.

PASSOS, Eduardo; KASTRUP, Virgínia e ESCÓSSIA, Liliana. Pistas do método da cartografia: Pesquisaintervenção e produção de subjetividade - Porto Alegre: Sulina, 2015.

PATROCÍNIO, Gabriel; NUNES, José Mauro (org.). Design \& Desenvolvimento: 40 anos depois. São Paulo. Blucher, 2015.

PORTELA, Raiama; Noronha, Raquel; Perpétuo, Nayara; Araújo, Railde; Santos, Ana Áurea; “O conhecimento tem que ser repartido!" Notas sobre identidade cultural, desenvolvimento de produtos e artesanato entre designers e um grupo extrativista de coco babaçu" p. 5613-5624 . In: Anais do 12을 Congresso Brasileiro de Pesquisa e Desenvolvimento em Design [= Blucher Design 
Proceedings, v. 9, n. 2]. São Paulo: Blucher, 2016. Disponível em:<https://www.proceedings.blucher.com.br/article-details/o-conhecimento-temque-serrepartido-notas-sobre-identidade-cultural-desenvolvimento-de-produtos-e-artesanatoentredesigners-e-um-grupo-extrativista-de-coco-babacu-25553>. Acessado em: 01 abr/2018.

THACKARA, John. Plano B: o design e as alternativas viáveis em um mundo de complexo. São Paulo. Saraiva: Versar, 2008. 